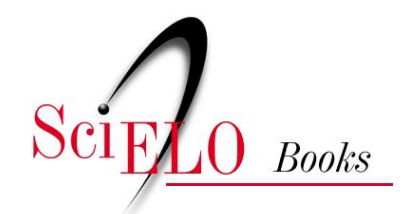

\title{
Uma comparação entre os Satãs do Paradise Lost e Paradise Regained
}

\author{
Paloma Catarina Zart
}

\section{SciELO Books / SciELO Livros / SciELO Libros}

ZART, PC. Uma comparação entre os Satãs do Paradise Lost e Paradise Regained. In MAGALHÃES, ACM., et al., orgs. O demoníaco na literatura [online]. Campina Grande: EDUEPB, 2012. pp. 139147. ISBN 978-85-7879-188-9. Available from SciELO Books <http://books.scielo.org>.

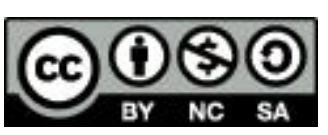

All the contents of this work, except where otherwise noted, is licensed under a Creative Commons Attribution-Non Commercial-ShareAlike 3.0 Unported.

Todo o conteúdo deste trabalho, exceto quando houver ressalva, é publicado sob a licença Creative Commons Atribuição Uso Não Comercial - Partilha nos Mesmos Termos 3.0 Não adaptada.

Todo el contenido de esta obra, excepto donde se indique lo contrario, está bajo licencia de la licencia Creative Commons Reconocimento-NoComercial-CompartirIgual 3.0 Unported. 


\section{Uma comparação entre os Satãs do Paradise Lost e Paradise Regained}

Paloma Catarina Zart (UFSM) ${ }^{18}$

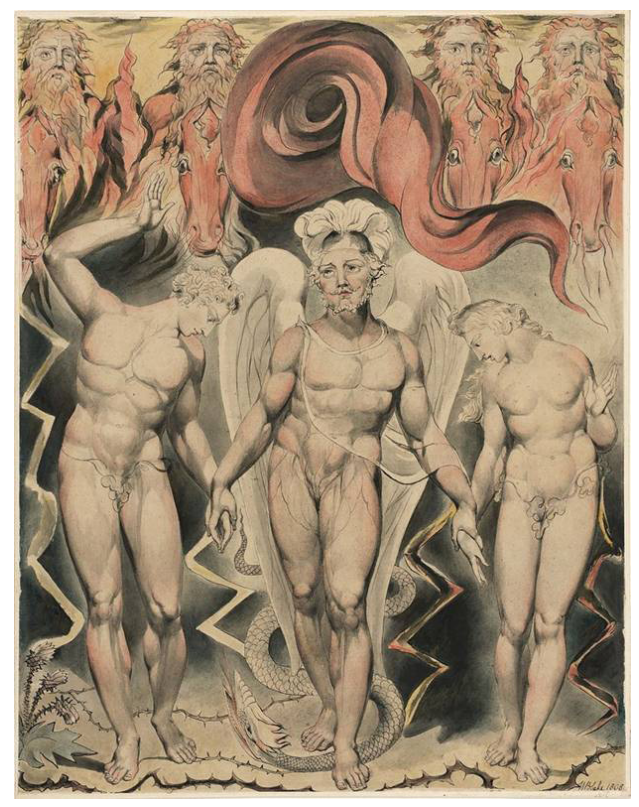

Barbara K. Lewalski (2003) lembra duas anedotas acerca dos épicos miltonianos. Ao fim da composição de Paradise Lost, Milton entregou o manuscrito a um amigo para que este o lesse, ao devolver o texto, o amigo haveria dito estar ansioso para ler a continuação do título. A outra anedota está ligada ao editor, responsável pela publicação do épico. Diante da boa aceitação do título miltoniano, o editor haveria pedido

18 Doutoranda pelo Programa de Pós-Gradução em Letras da Universidade Federal de Santa Maria. Bolsista CAPES. Email: paloma.zart@gmail.com 
um segundo livro. Surgiria destes pedidos a primeira ideia para o Paradise Regained. Independente da veracidade dos episódios é constantemente levantada a possível sequência entre eles, algo fortalecido pela semelhança entre os títulos, bem como pelas suas temáticas. Enquanto que Paradise Lost narra a perda do paraíso terrestre e, em consequência, do celeste; Paradise Regained apresenta a promessa da recuperação do paraíso áureo, revelando, com isso, um movimento contínuo. Ao nosso entender, no entanto, os épicos não são uma continuidade, prova disto está nas personagens dos títulos, em especial na representação de Satã apresentada nas duas obras. Os diabos são distintos ao ponto de terem como única semelhança o nome que envergam e a função tentadora que exercem sobre outras personagens. Analisados em profundidade, os dois Satãs são tão distintos quanto o dia da noite.

Várias são as fontes de influência que podem ter sido utilizadas por Milton para a construção do Satã do Paradise Lost, ao passo que o Satã do Paradise Regained encaixa-se somente em uma destas fontes ${ }^{19}$. Neil Forsyth (2003) lembra, sumariamente, o complexo espectro de possíveis construções para a compreensão de S1, sendo que a análise da personagem pode variar da perspectiva puramente literária, com suas raízes na literatura grega, até a uma abordagem exclusivamente teológica. Essa gama de possíveis aproximações torna extremamente flexível uma determinação da personagem como, por exemplo, protagonista ou antagonista no épico, tudo dependendo da perspectiva argumentativa adotada.

O mito do combate é exemplar desta maleabilidade. Assevera Forsyth (2003) que o mito está relacionado com a polarização de forças, sendo uma delas dominante, enquanto a outra, dominada, tenda destronar a primeira. Uma análise inicial deste espectro coloca em posições fixas os polos, há um rebelde que, normalmente, será considerado como o lado negativo. A simples observação de qual dos dois postos é ocupado por quem, no entanto, não encerra a complexidade envolvida neste mito. Na Teogonia, Hesíodo apresenta uma versão do mito do combate. Nele, Zeus é apresentado como o lado positivo, apesar de ser o rebelde. A construção da narrativa permitiu que Hesíodo apresentasse Urano como um déspota, capaz de devorar sua prole para defender sua posição. Neste

19 Para fins de desambiguação o Satã do Paradise Lost será nomeado, doravante, S1, enquanto que o Satã do Paradise Regained, S2 
caso, a revolta de Zeus, observa Forsyth (2003), embasada no destronamento de um tirano, passa a ser vista como positiva e aceitável. Ou seja, a construção narrativa de Hesíodo, escolhendo o lado de Zeus, reverte a noção inicial do mito do combate (Forsyth, 2003).

A presença massiva de fontes, mitos e episódios, no Paradise Lost, permitiu a Milton construir uma personagem que não pode ser determinada, sem perdas significativas. Em Paradise Regained, porém, o domínio de uma única fonte, o relato de Lucas, e uma ação singular, a tentação de Jesus no deserto, crava a caracterização de S2.

\section{A complexidade de Satã no Paradise Lost}

Uma personagem redonda, definida por E.M. Forster (2010), é aquela capaz de surpreender de modo convincente. Ainda, é impossível, continua Forster, defini-la em uma sentença ou lembra-la por si só, ou seja, sem elencá-la a um conjunto de episódios. O crítico, ao fazer essas afirmações, pensava na personagem de romance, mas as assertivas são extensíveis a outros gêneros. Ao Satã do Paradise Lost, por exemplo, as definições são muito apropriadas, pois, não é possível defini-lo somente como o tentador do homem que busca vingança, e, ainda, a percepção desta personagem envolve a indicação de cenas. Em suma, S1 exige mais esforço daqueles que tentam analisá-lo.

A complexidade de Satã está relacionada às posições assumidas ao longo da narrativa épica, bem como nas relações estabelecidas com outras personagens. Passado e presente de S1 são relatados no épico, revelando a evolução da personagem e a necessidade que enfrenta para se adaptar e compreender o que está vivenciando. Para tanto, em determinadas situações, o anjo rebelado precisa enfrentar seus fantasmas e definir sua posição. Os solilóquios são a representação deste momento crucial, pois, é quando S1, sozinho e tendo diante de si toda a criação, se deixa conduzir por todos os pensamentos que o atormentam. Nestes momentos, Satã é triforme (Carey, 2008), uma vez que apresenta traços de seu passado angélico - como arcanjo - e as marcas de seu presente infernal - como Príncipe das Trevas e serpente tentadora. 
Para John Carey, o entendimento de que a queda angélica é de responsabilidade do próprio arcanjo representa um destes momentos em que a natureza triforme de Satã é evidente:

In it, Satan concedes his own criminality, and his own responsibility for his fall. He vacillates between remorse and defiance. He confesses that his rebellion was completely unjustifiable, that he had the same 'free will and power to stand' as all God's creatures, and that he therefore has nothing to accuse but 'heaven's free love dealt equally to all'. Since heaven's love means his own damnation, he curses it ('Be then his love accursed'), but then, rationally, turns his curse against himself ('Nay, cursed be thou'). Satan could be called evil at this point of the poem only in some attenuated sense, since he speaks the truth and curses himself as God curses him. He and God are in accord. (CAREY, 2008, p. 163) ${ }^{20}$

A admissão de culpa, porém, não significa o cessar dos conflitos de Satã ou a aceitação pacífica do destino que aguarda o anjo. Os embates internos continuam ao longo da narrativa épica e são superados na medida em que S1 aceita, definitivamente, sua condição de caído. A reiterada afirmação do mal, que finaliza os cinco solilóquios satânicos provam a constante necessidade de lembrar a nova posição da personagem na estrutura tripartida do universo. Admitir a queda está relacionado à compreensão da perda e a aceitação de um papel secundário. $\mathrm{O}$

20 Nele [primeiro solilóquio], Satã reconhece sua criminalidade e sua responsabilidade pela queda. Ele vacila entre remorso e provocação. Confessa que sua rebelião era injustificável e que tinha o mesmo 'livre-arbítrio e força para permanecer' como todas as criaturas divinas, portanto, não tinha nada a acusar senão 'o livre amor do céu igualmente distribuído'. Uma vez que o amor celeste significa sua própria condenação, ele o amaldiçoa ('Seja seu amor amaldiçoado'), mas, em seguida, racionalmente, transfere sua maldição a si ('Não, seja tu amaldiçoado'). Satã pode ser chamado de mal, neste ponto do poema, somente em um sentido atenuado, pois fala a verdade e amaldiçoa a si como Deus o amaldiçoa. Ele e Deus estão de acordo. Tradução da autora. 
reconhecimento do amor divino, como enfatiza Carey (2008), demonstra que Satã não esqueceu completamente sua posição na hierarquia celeste, no qual seu papel estava delimitado de acordo com o que era esperado dos anjos.

David Masson (1874) defende que a queda fora mais prejudicial ao seu líder do que aos outros anjos que o seguiram. Ainda no primeiro solilóquio, Satã lembra o sentimento de eterna dívida imposto sobre os seres celestes ("The debt immense of endless gratitute,/ So burdensome still paying, still to owe; $)^{21}$, condenados a pagar com honrarias e louvores um débito não compreendido. Fruto do tempo, mas sem registros do momento, a personagem indaga a capacidade divina para gerar a vida e acredita que sua existência resulta da autocriação. Durante o concílio rebelde, ainda nos domínios celestes, ao proclamar-se capaz de criar, o arcanjo se equipara com Deus e evidencia a visão equivocada do poder que detinha na estrutura celestial. Masson (1874) atribui a uma inabilidade de assimilar a própria posição um dos motivos por trás da queda do anjo. Como um dos quatro arcanjos, Satã era designado para executar ordens divinas. Para tanto, era-lhe concedida uma parcela de poder, a qual the permitia o cumprimento das demandas. Inebriado por este poder momentâneo e limitado, a personagem passa a acreditar que essa faculdade concedida lhe pertencia de fato e de direito.

Após a queda, algumas situações permitem que Satã viva essa posição de poder. Diante das hostes caídas e de seus herdeiros, Pecado e Morte, o anjo posiciona-se de modo a respaldar uma posição hierárquica superior e paternal. A postura assumida por Satã nestes episódios é distinta daquela testemunhada quando a personagem encontra-se sozinha. Nos discursos para as hostes e os herdeiros, S1 revela uma certeza e segurança inexistente nos solilóquios. Isso ocorre porque há uma necessidade de convencer aos outros sobre o percurso percorrido - a guerra celeste e a reclusão no inferno - a fim de angariar o auxílio dos mesmos na execução de novos planos - a tomada do Éden e corrupção de seus habitantes.

21 O débito imenso de eterna gratidão/ Oneroso, sempre pagando e sempre devendo. Tradução da autora. 
Diante de testemunhas, o ex-anjo assume a liderança e demonstra uma segurança que não corresponde com as dúvidas e as incertezas expostas nos solilóquios. A natureza triforme de Satã, apontada por Carey (2008), revela-se nesta contradição entre o exterior e o interior da personagem. A ação, representada na segurança exterior, contraposta à observação dos fatos, apresentada nos solilóquios, vem confirmar a afirmação de Masson (1874), de que o Satã miltoniano, do Paradise Lost, vive um momento de escolha, na qual precisa decidir sua posição, assumindo-se, definitivamente, como o adversário e, consequentemente, esquecendo qualquer possibilidade de perdão.

\section{A linearidade de Satã no Paradise Regained contraposta à complexidade de Paradise Lost}

Defendemos a tese de que os Satãs do Paradise Lost e do Paradise Regained não são os mesmos. $\mathrm{O}$ argumento basilar desta hipótese encontra-se nas divergências entre as duas personagens. A primeira delas refere-se ao grau de complexidade com que são representadas por Milton. Enquanto S1 é uma personagem redonda, S2 é plana. Posto que, contrária à personagem dita redonda, a plana, lembra Forster (2010), é aquela que não passa por nenhum processo que resulte em alguma modificação no modo como ela age ou em suas crenças. Novamente, deve-se observar, as colocações de Forster foram apresentadas com relação à personagem de romance, mas podem ser úteis na compreensão de atores em outros gêneros.

De modo análogo com a simplicidade da personagem, a trama de Paradise Regained também é simples. Completamente centrada na tentação de Jesus no deserto, o épico está embasado na história de Jó, considerada modelo por Milton, e em Lucas (RADZINOWICZ, 2008). Não há oscilação temporal na peça ou qualquer modificação na polarização entre as personagens. Tudo, inclusive os atores, é voltado para a ação singular que transcorre no épico, ao ponto de Kerrigan, Rumrich e Fallon (2007) observarem que tanto o Satã quanto o Cristo representado na narrativa não lembram seu passado: 
We deduce that while Satan knows that Jesus is the woman's seed destined to bruise his head [...] he does not recognize in Jesus the Son of Book 6 of Paradise Lost, whose elevation prompted his envious rebellion and whose decisive appearance on the third day of the war drove him and his troops from Heaven. Jesus also indicates no knowledge of those cosmic events. He understands by searching the Scriptures that he is the prophesied Messiah, destined to redeem mankind and deliver a weakening blow to Satan [...] but he does not realize that defeating Satan belongs to his divinity as much as to his humanity. (p. 634) ${ }^{22}$

A observação dos críticos reforça a compreensão de que as personagens demoníacas representadas nos dois épicos miltonianos não são, de fato, a mesma. Caso a hipótese fosse válida, teríamos de encontrar no Paradise Regained um Satã capaz de recordar e reconhecer seu inimigo dos tempos cósmicos. Tem-se no épico, no entanto, uma personagem que pode ser facilmente aproximada, em um sentido muito largo, das morality plays medievais, posto que o sentido didático destas parece estar presente no último escrito de Milton. Morality plays, de acordo com a definição da Enciclopédia Britânica, são dramas alegóricos em que lições morais eram ensinadas por meio de personagens que personificavam qualidades morais ou abstrações.

Uma terceira divergência está no modo como o antagonismo entre Satã e Jesus é construído. O diabo apresentado no Paradise Regained lembra a mão esquerda de Deus, uma vez que ele age conforme estabelecido, conduzindo as tarefas sujas necessárias para a realização dos desígnios divinos, de modo bastante semelhante à compreensão de Luther Link

22 Deduzimos que enquanto Satã sabe que Jesus é a semente da mulher destinada a pisar sua cabeça [...] ele não reconhece em Jesus o Filho do canto 6 do Paradise Lost, cuja elevação provocou sua inveja e cuja aparição decisiva no terceiro dia de guerra lançou-o e suas tropas para fora do Céu. Jesus também não demonstra nenhum conhecimento destes eventos cósmicos. Ele compreende, pela leitura da Escritura, ser o Messias profetizado, destinado para redimir a humanidade e desferir o golpe final em Satã [...] mas ele não entende que vencer Satã pertence a sua divindade tanto quanto à sua humanidade. Tradução da autora. 
(1998) sobre o papel desta figura mutável e nefanda que acompanha a sociedade ocidental. Não há questionamentos por sua parte, mas a simples aceitação do papel a ser desempenhado. Isso lembra, novamente, Masson (1874) e encerra a questão, momentaneamente.

A distinção maior entre os dois Satãs está no fato de S1 ter um passado, um presente e a perspectiva de um futuro, ao passo que S2 não tem passado ou futuro, somente o presente no qual cumpre sua tarefa. Afirmamos que o Satã do Paradise Lost é vítima da culpa cristã ao passo que o Satã do Paradise Regained está livre dela. 


\section{Bibliografia}

CAREY, J. Milton's Satan. IN: DANIELSON, D. (ed.). Cambridge

Companion to Milton. Cambridge: Cambridge University Press, 2nd ed. 8th print, 2008, p. $160-174$.

ENCYCLOP EDIA BRITANNICA. Em sua versão digital disponível em http://www.britannica.com/EBchecked/topic/391805/morality-play

FORSTER, E. M. Aspects of the novel. New York: RosettaBooks, 2010. Versão digital para e-readers.

FORSYTH, N. The Satanic Epic. Princenton: Princenton University Press, 2003.

KERRIGAN, W.; RUMRICH, J.; FALLON, S. The complete poetry and essential prose of John Milton. New York: Modern Library, 2007.

LEWALSKY, B. K. John Milton: a critical biography. Oxford: Blackwell Publishing, 2003.

LINK, L. O Diabo: a máscara sem rosto. Tradução Laura Teixeira Mota. São Paulo: Companhia das Letras, 1998.

MASSON. D. Three Devils: Luther's, Milton's and Goethe's. IN: Three Devils: Luther's, Milton's, and Goethe's. With other essays. London: Macmillan \& Co, 1874, p. 3-58.

MILTON, J. Paradise Lost; Paradise Regained. IN: KERRIGAN, W.; RUMICH, J.; FALLON, S.M. (eds.) The Complete Poetry and Essential Prose of John Milton. New York: Modern Library, 2007, p. 251 - 630; $631-697$.

RADZINOWICZ, M. A. How Milton read the Bible: the case of Paradise Regained. IN: DANIELSON, D. (ed.). Cambridge Companion to Milton. Cambridge: Cambridge University Press, 2nd ed. 8th print, 2008, p. 202-218.

\section{Imagem:}

Expulsão do Paraíso, William Blake. Disponível em http://escamandro. files.wordpress.com/2012/06/william_blake-the_expulsion_of_adam_and_ eve_from_the_garden-of-eden.jpg 
